\title{
ASSESSMENT OF BIOLOGICAL SAFETY OF FERMENTED PHYLLANTHUS EMBLICA FRUIT JUICE
}

\section{CHAIYAVAT CHAIYASUT ${ }^{1 *}$, BHAGAVATHI SUNDARAM SIVAMARUTHI ${ }^{1}$, YODSAWEE DUANGJITCHAROEN ${ }^{2}$ PERIYANAINA KESIKA ${ }^{1}$, SASITHORN SIRILUN ${ }^{1}$, KHONTAROS CHAIYASUT T ${ }^{3,4}$, SARTJIN PEERAJAN ${ }^{4}$}

${ }^{1}$ Department of Nutraceuticals and Cosmeceuticals, Innovation Center for Holistic Health, Faculty of Pharmacy, Chiang Mai University Chiang Mai-50200, Thailand. ${ }^{2}$ Division of Biopharmacy, Faculty of Pharmaceutical Sciences, Burapha University, Chonburi-20131,

Thailand. ${ }^{3}$ Institute of Research and Development, Chiang Mai Rajabhat University, Chiang Mai-50300, Thailand. ${ }^{4}$ Health Innovation Institute, Chiang Mai -50200, Thailand. Email: chaiyavat@gmail.com

Received: 04 May 2018, Revised and Accepted: 29 May 2018

\section{ABSTRACT}

Objective: The present study evaluated the subchronic toxicity of Lactobacillus mediated fermented Phyllanthus emblica fruit juice (FPJ) using a rat as a model system.

Methods: FPJ was prepared, and estimated the changes in $\mathrm{pH}$ by $\mathrm{pH}$ meter, and microbial load by a plating method. Rats were fed with different dose of FPJ for 60 days. The changes in the body mass were noted. The blood and organs of the experimental rats were collected, after 60 days of intervention. Then, they were analyzed for the selected hematological and biochemical parameters by following standard hospital protocols.

Results: The pH of FPJ after 30 days of fermentation was 3.16. FPJ was rich in probiotic Lactobacillus spp. (7.23 Log CFU per mL) without contamination. The supplementation of FPJ was not significantly affected the body weight of the experimental animals, except the female rats in posteffective dose (PED) group showed significant changes $(20.83 \pm 8.49 \mathrm{~g})$ compared to control $(40 \pm 17.22 \mathrm{~g})$. The internal organs of the rat were not affected by the FPJ supplementation. The changes observed in blood urea nitrogen, creatinine, cholesterol, triglyceride, aspartate aminotransferase; alanine aminotransferase, and alkaline phosphatase level of experimental rats, both male and female, were not significantly differed from the respective controls. The average of lymphocytes level was significantly increased in continuous dosing group of males and females. Interestingly, the increase in red blood cell and hemoglobin (HGB) were statistically significant for ED group and PED in both sexes, except for females with no effect on HGB content.

Conclusion: The prepared FPJ was enriched with probiotic Lactobacillus spp. The supplementation of FPJ (up to $9 \mathrm{~mL} / \mathrm{kg} / \mathrm{day}$ ) for 60 days was not significantly influenced the body weight, internal organs, biochemical and hematological parameters of experimental rats (both male and female). The results revealed that $\mathrm{FHJ}$ is suitable for the human consumption.

Keywords: Phyllanthus emblica, Lactic acid bacteria, Fermented plant juice, Subchronic, Toxicity.

(C) 2018 The Authors. Published by Innovare Academic Sciences Pvt Ltd. This is an open access article under the CC BY license (http://creativecommons. org/licenses/by/4. 0/) DOI: http://dx.doi.org/10.22159/ajpcr.2018.v11i9.27104

\section{INTRODUCTION}

Phyllanthus emblica, also known as Emblica officinalis, Indian gooseberry, emblic, belongs to Phyllanthaceae family. P. emblica is one of the commonly used medicinal herbs in traditional Indian medicine. P. emblica is rich in phytonutrients, proteins, fibers, fat, vitamins (especially Vitamin-C), minerals, and trace elements (calcium, chromium, copper, iron, magnesium, nicotinic acid, phosphorus, potassium, and zinc) [1]. Almost all the part of P. emblica plant (fruit, root,and leaves) was reported for health benefits and pharmacological importance such as anti-inflammation, antihyperglycemia, anti-hyperlipidemia, anticancer, anti-mutagenic, anti-pyretic, anti-microbial, anti-diarrheal, anti-hyperthyroidism, anti-venom cardioprotective, neuroprotective, etc., [2-20]. P. emblica is consumed as raw fruit, fruit juice, fermented fruit juice, pickles, and powder forms. P. emblica fruit pickling is most common practice in southern India, which has been consumed by the people every day along with regular diet. Southeast Asians widely use the fermented P. emblica fruit juice (FPJ). The fermentation of plant materials with desired microbial starter culture improved the nutritional value and bioactive compounds [21-23].

Fermentation is an ancient method of preparing, improving and preserving the food. Asian peoples extensively use the fermented foods, and they believe that fermented foods are a cure for several diseases [24]. The microbes isolated from naturally fermented foods are reported for glutaminase, and glutamate decarboxylase, and $\gamma$-aminobutyric acid-producing ability $[25,26]$. The fermented plant juices are reported for several pharmacological applications. For example, the supplementation of lactic acid bacteria (LAB) fermented mushroom juice help to diminish the diabetic consequences [27]. Lactobacillus paracasei HII01 mediated fermented P. emblica exhibited high polyphenolic compounds, and enhanced free-radical scavenging activity compared to control [21].

Though $P$. emblica is used in several traditional medicines, the reports on fermented LAB mediated FPJ is inadequate. The supplementation of $0.5 \mathrm{~g} / \mathrm{kg}$ of P. emblica leaves aqueous extract (PLAE), and $10 \mathrm{~g} / \mathrm{kg}$ of an ethanolic extract of emblica fruit (EEEF) were not shown any toxicity in mice. Whereas, intraperitoneal injection of PLAE and EEEF exhibited LD50 of $0.288-0.415$, and $4.8 \mathrm{~g} / \mathrm{kg}$ body weight of mice, respectively $[28,29]$.

There was no subchronic toxicity study on LAB-mediated FPJ. The present study was executed to evaluate the subchronic toxicity of L. paracasei HII01 mediated fermented P. emblica using rodent model system.

\section{METHODS}

\section{Preparation of FP]}

The inoculum preparation and fermentation process were performed as detailed in a previous study [21]. Briefly, the crushed P. emblica fruits, sterile water, and cane sugar were mixed in the ratio of 3:10: 1, and sterilized. Then, $10 \%$ of $L$. paracasei HIIO1 was inoculated, and fermented for 30 days. 
pH, and microbial load

The $\mathrm{pH}$ of FPJ was kinetically measured using $\mathrm{pH}$ meter (Inola, $\mathrm{pH}$ level 2, Weilheim) [21]. The microbial load of FPJ was determined by spread plate method using specific media as prescribed earlier [30].

\section{Animals, intervention, and sample collection}

The Sprague Dawley rats of 150-180 g of weight, obtained from National Laboratory Animal Center of Mahidol University, Thailand, were casually divided into groups. The test intervention was $1.2 \mathrm{~mL} / \mathrm{kg} /$ day of FPJ (effective dose [ED]), $9.00 \mathrm{~mL} / \mathrm{kg} /$ day of FPJ (high dose [HD]) for 60 days, and $1.2 \mathrm{~mL} / \mathrm{kg} /$ day of FPJ (post-ED [PED]) for 53 days along with standard animal feed. The control animals were fed with laboratory food and drinking water for 60 days. After 60 days of study, blood and internal organs of the experimental rats were collected for inspection. The experiments were ethically approved by the Ethical Committee of Faculty of Medicine, Chiang Mai University (CMU) (Approved protocol no: $1 / 2552$ dated 23 June 2009)

Measurement of body mass and assessment of hematological and biochemical parameters

The difference in weight of experimental rats was recorded using laboratory weighing machine. The weight of internal organs (brain, liver, spleen, eyes, heart, lung, kidneys, stomach, and adrenal gland) was measured. The change in the weight was calculated by the following formula.

Deviations in weight $=$ Final weight - Initial weight .

The biochemical and hematological parameters (hemoglobin [HGB], hematocrits, white blood cell (WBC) count, polymorphonuclear cell, lymphocyte, platelets, red blood cell (RBC) count, level of aminotransaminase, alanine aminotransaminase, alkaline phosphatase [ALP]) were measured at MT InterMed (Hosptial) Growth Diags Co., Ltd., Ching Mai, Thailand, as per the standard procedures.

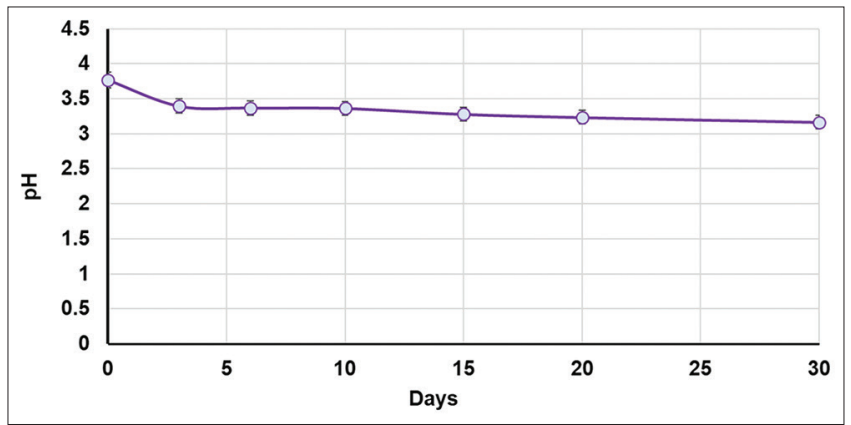

Fig. 1: The changes in the pH of fermented Phyllanthus emblica fruit juice

\section{Statistical analysis}

The experiments were completed in triplicate. The values were signified as a mean \pm standard deviation. Duncan's new multiple range tests determined the significant differences, at the $95 \%$ confidential level $(\mathrm{p}<0.05)$ by SPSS v.17 (Chicago, SPSS Inc, U.S.A).

\section{RESULTS AND DISCUSSION}

The fermentation of $P$. emblica fruit juice (FPJ) was carried out. The $\mathrm{pH}$ of FPJ was gradually reduced during fermentation. The $\mathrm{pH}$ of initial day of fermentation was 3.76, while after 30 days of fermentation the $\mathrm{pH}$ was 3.16 (Fig. 1).

The microbial content of FPJ was increased during fermentation. After thirty days of fermentation, total bacterial count, and Lactobacillus spp. count was found as 7.39, and 7.23 Log CFU per mL, respectively. At 3-6 days of fermentation high concentration of Lactobacillus spp. (8.33-8.63 Log CFU per mL) was observed in FPJ. Then, the number of Lactobacillus spp. was reduced steadily, possibly due to the depletion of nutrients. Yeast and Bacillus spp. were not found in FPJ at any point of fermentation, which suggested that FPJ was microbiologically safe (Fig. 2).

The average body weight of ED, HD, and PED group male rats was $104.29 \pm 31.47,98.57 \pm 28.24$, and $115.83 \pm 20.66$ g, respectively, while control rat was $123.33 \pm 30.33 \mathrm{~g}$ after 60 days of the experimental period. The average body weight of ED, HD, and PED group female rats was $33.57 \pm 13.14,32.86 \pm 12.2$, and $20.83 \pm 8.49$ g, respectively while control rat was $40.00 \pm 17.22 \mathrm{~g}$ after 60 days of the experimental period. There were no significant changes in body weight of male rats supplemented with FPJ, irrespective of dose (ED, HD, and PED). Whereas, female rats in PED group showed significant changes $(20.83 \pm 8.49 \mathrm{~g})$ compared to

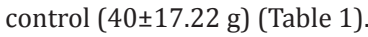

Animals were euthanized after the intervention of FPJ for 60 days. The organs (brain, eyes, heart, lung, liver, spleen, stomach, kidneys, and adrenal gland) were collected for macroscopic examination and weighed. There were no significant treatment-related pathological changes observed in any organ of the experimental rats at all tested dose levels when compared with organs in control animals (Table 2). The changes observed in blood urea nitrogen, creatinine, cholesterol, triglyceride, aspartate aminotransferase; alanine aminotransferase, and ALP level of experimental rats, both male and female, were not significantly differed from the respective controls (Table 3 ).

The tested hematological parameters were significantly varied from control (Table 3). The average of WBC, hematocrits, and platelets level was not altered significantly in male rats of all groups. The average WBC, HGB, hematocrits levels were not changed in female rats of ED group. The average of lymphocytes level was significantly increased

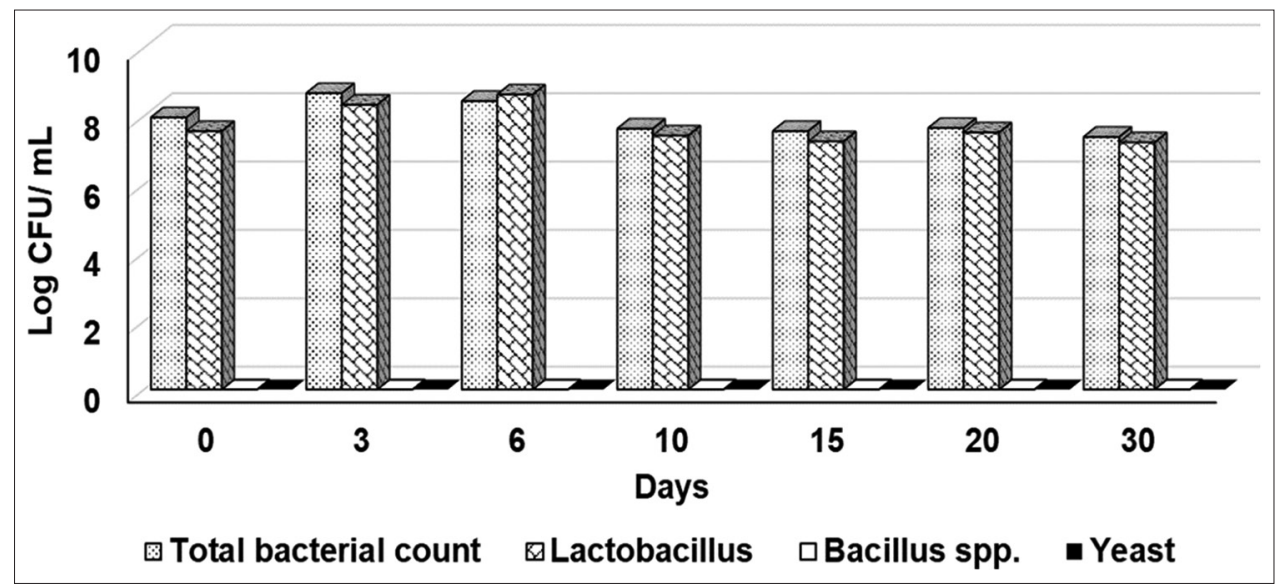

Fig. 2: Microbial load in Phyllanthus emblica fruit juice during fermentation 
Table 1: The difference in body mass of test animals during the experimental period. The values were derived from the baseline values

\begin{tabular}{|c|c|c|c|c|c|c|c|c|}
\hline \multirow[t]{3}{*}{ Day } & \multicolumn{8}{|c|}{ Body weight (g) } \\
\hline & \multicolumn{4}{|l|}{ Male } & \multicolumn{4}{|l|}{ Female } \\
\hline & Control & ED* & HD $^{* *}$ & PED*** & Control & ED* & HD $^{* *}$ & PED*** \\
\hline 5 & $15.00 \pm 11.69$ & $12.14 \pm 4.15$ & $16.43 \pm 7.18$ & $10.00 \pm 2.94$ & $6.67 \pm 3.29$ & $8.57 \pm 0.29$ & $6.43 \pm 0.32$ & $5.00 \pm 1.36$ \\
\hline 15 & $40.00 \pm 17.51$ & $24.29 \pm 8.56$ & $25.00 \pm 6.59$ & $38.33 \pm 13.93$ & $12.50 \pm 3.20$ & $6.07 \pm 2.29$ & $9.51 \pm 3.57$ & $8.61 \pm 0.00$ \\
\hline 30 & $88.33 \pm 20.74$ & $55.00 \pm 18.7$ & $60.00 \pm 27.06$ & $78.33 \pm 15.94$ & $29.17 \pm 12.81$ & $15.00 \pm 9.57$ & $16.43 \pm 4.27^{\#}$ & $13.33 \pm 7.58^{\# \#}$ \\
\hline 60 & $123.33 \pm 30.33$ & $104.29 \pm 31.47$ & $98.57 \pm 28.24$ & $115.83 \pm 20.66$ & $40.00 \pm 17.22$ & $33.57 \pm 13.14$ & $32.86 \pm 12.2$ & $20.83 \pm 8.49^{\# \#}$ \\
\hline
\end{tabular}

*ED: $1.2 \mathrm{ml} / \mathrm{kg} /$ day, ${ }^{* *} \mathrm{HD}: 9 \mathrm{ml} / \mathrm{kg} /$ day, ${ }^{* * *}$ PED: Post-effective dose (intervention has been stopped before 7 days of final assessments). ${ }^{*}$ Significant difference (p<0.05) between control and test-group; "\#significant difference $(\mathrm{p}<0.01)$ between control and test group. ED: Effective dose, HD: High dose

Table 2: Changes in the organ weight after oral supplementation of fermented $P$. emblica juice. The values were derived from the control values (the difference between control value and experimental value, after the experimental period), and were represented as a mean \pm standard deviation

\begin{tabular}{|c|c|c|c|c|c|c|}
\hline \multirow[t]{3}{*}{ Organs } & \multicolumn{6}{|l|}{ Weight (g) } \\
\hline & \multicolumn{3}{|l|}{ Male } & \multicolumn{3}{|l|}{ Female } \\
\hline & $1.2 \mathrm{ml} / \mathrm{kg} /$ day (ED) & $9 \mathrm{ml} / \mathrm{kg} /$ day (HD) & PED & $1.2 \mathrm{ml} / \mathrm{kg} /$ day (ED) & $9 \mathrm{ml} / \mathrm{kg} /$ day (HD) & PED \\
\hline Brain & $-0.06 \pm 0.11$ & $-0.02 \pm 0.05$ & $-0.26 \pm 0.43$ & $0.01 \pm 0.02$ & $0.02 \pm 0.10$ & $-0.21 \pm 0.57$ \\
\hline Eyes & $-0.03 \pm 0.05$ & $-0.021 \pm 0.04$ & $0.42 \pm 0.79$ & $-0.02 \pm 0.07$ & $0 \pm 0.02$ & $0.05 \pm 0.2$ \\
\hline Heart & $-0.02 \pm 0.39$ & $0.129 \pm 0.41$ & $0.17 \pm 0.55$ & $-0.2 \pm 0.30$ & $-0.22 \pm 0.24$ & $-0.31 \pm 0.44$ \\
\hline Lung & $0.29 \pm 0.98$ & $-0.2648 \pm 0.43$ & $0.08 \pm 0.82$ & $-0.19 \pm 0.43$ & $-0.16 \pm 0.56$ & $-0.11 \pm 0.79$ \\
\hline Liver & $-0.41 \pm 2.15$ & $-1.55 \pm 1.3$ & $-1.09 \pm 2.38$ & $-5.03 \pm 0.69$ & $-4.78 \pm 0.62$ & $-5.88 \pm 1.77$ \\
\hline Spleen & $-0.09 \pm 0.09$ & $-0.11 \pm 0.05$ & $-0.11 \pm 0.12$ & $-0.04 \pm 0.05$ & $-0.12 \pm 0.22$ & $-0.14 \pm 0.19$ \\
\hline Stomach & $-0.22 \pm \pm 0.95$ & $0.17 \pm 0.28$ & $0.04 \pm 0.13$ & $0.14 \pm 0.12$ & $0.11 \pm \pm 0.11$ & $-0.06 \pm 0.55$ \\
\hline Kidneys & $-0.04 \pm 0.27$ & $-0.13 \pm 0.23$ & $-0.33 \pm 0.42$ & $0.11 \pm 0.11$ & $0.17 \pm 0.15$ & $-0.09 \pm 0.62$ \\
\hline Adrenal Grand & $-0.01 \pm 0.02$ & $-0.02 \pm 0.02$ & $-0.02 \pm 0.02$ & $0.02 \pm 0.01$ & $0.02 \pm 0.01$ & $0 \pm 0.03$ \\
\hline
\end{tabular}

P. emblica: Phyllanthus emblica, ED: Effective dose, HD: High dose, PED: Post-effective dose

Table 3: Effect of supplementation of fermented P. emblica juice on the hematological and biochemical parameters in hamster after 60 days of treatment. The values were derived from the control values (the difference between control value and experimental value, after the experimental period) and were represented as a mean \pm standard deviation.

\begin{tabular}{|c|c|c|c|c|c|c|}
\hline \multirow[t]{2}{*}{ Parameters } & \multicolumn{3}{|l|}{ Male } & \multicolumn{3}{|l|}{ Female } \\
\hline & ED & HD & PED & ED & HD & PED \\
\hline \multicolumn{7}{|c|}{ Hematological parameters } \\
\hline $\operatorname{RBC}\left(10^{6} / \mathrm{mm}^{3}\right)$ & $-3.9 \pm 0.18^{* *}$ & $-0.26 \pm 0.19$ & $-0.52 \pm 0.19 * *$ & $-0.21 \pm 0.08^{*}$ & $-0.22 \pm 0.07$ & $-0.23 \pm 0.12 *$ \\
\hline WBC $\left(10^{3} / \mathrm{mm}^{3}\right)$ & $0.34 \pm 0.26$ & $0.16 \pm 0.20$ & $0.04 \pm 0.25$ & $0.24 \pm 0.19$ & $0.13 \pm 0.20$ & $0.46 \pm 0.25$ \\
\hline $\mathrm{HGB}(\mathrm{g} / \mathrm{dL})$ & $-1.08 \pm 0.61 *$ & $-0.83 \pm 0.58$ & $-1.12 \pm 0.33^{*}$ & $-0.64 \pm 0.50$ & $-0.16 \pm 0.58$ & $-0.92 \pm 0.92$ \\
\hline Hematocrits (mL\%) & $-3.29 \pm 1.80$ & $-2.57 \pm 1.81$ & $-3.33 \pm 1.03$ & $2.50 \pm 1.47$ & $3.42 \pm 1.26$ & $2.17 \pm 2.74$ \\
\hline Lymphocyte (mL\%) & $-7.90 \pm 3.1^{*}$ & $-10.33 \pm 8.04 *$ & $-6.16 \pm 2.64$ & $-11.5 \pm 2.83^{* * *}$ & $-9.64 \pm 3.53^{* *}$ & $-10.00 \pm 4.37 *$ \\
\hline Platelets $\left(10^{3} / \mathrm{mm}^{3}\right)$ & $15.84 \pm 11.13$ & $15.84 \pm 11.13$ & $15.50 \pm 19.00$ & $-31.21 \pm 16.33^{*}$ & $-16.93 \pm 13.95$ & $-11.33 \pm 26.63$ \\
\hline \multicolumn{7}{|c|}{ Biochemical parameters } \\
\hline B.U.N. (mg/dL) & $2.84 \pm 7.10$ & $6.00 \pm 4.71$ & $12.34 \pm 8.61$ & $7.33 \pm 6.44$ & $-4.86 \pm 2.95$ & $2.00 \pm 4.09$ \\
\hline Creatinine (mg/dL) & $0.35 \pm 0.63$ & $-0.14 \pm 1.24$ & $-0.02 \pm 1.36$ & $0.63 \pm 0.94$ & $-0.05 \pm 1.42$ & $0.48 \pm 1.03$ \\
\hline Cholesterol (mg/dL) & $-20.00 \pm 16.34$ & $-6.5 \pm 44.23$ & $6.17 \pm 76.79$ & $0.5 \pm 39.69$ & $5.19 \pm 65.99$ & $20.17 \pm 89.36$ \\
\hline $\mathrm{TG}(\mathrm{mg} / \mathrm{dL})$ & $-4.67 \pm 7.87$ & $1.16 \pm 11.34$ & $4.83 \pm 10.64$ & $18.83 \pm 9.81$ & $15.90 \pm 9.57$ & $13.83 \pm 9.33$ \\
\hline AST (IU/L) & $-11.17 \pm 25.37$ & $-24.17 \pm 29.46$ & $-12.57 \pm 30.02$ & $0.2 \pm 32.33$ & $-0.71 \pm 26.37$ & $7.6 \pm 24.96$ \\
\hline ALT (IU/L) & $-0.33 \pm 5.00$ & $3.50 \pm 6.77$ & $-5.33 \pm 6.71$ & $2.33 \pm 4.37$ & $-0.46 \pm 5.12$ & $3.83 \pm 4.58$ \\
\hline ALP (IU/L) & $3.08 \pm 9.06$ & $10.58 \pm 2.94$ & $11.08 \pm 3.71$ & $7.77 \pm 8.73$ & $9.74 \pm 4.71^{*}$ & $11.43 \pm 2.04 *$ \\
\hline
\end{tabular}

*Significant difference $(\mathrm{p}<0.05)$ between control and test-group, ${ }^{* *}$ significant difference $(\mathrm{p}<0.01)$ between control and test group. ${ }^{* * *}$ Significant difference $(\mathrm{p}<0.001)$ between control and test-group. RBC: Red blood cells, WBC: White blood cells, HGB: Hemoglobin; PMNC: Polymorphonuclear cell; BUN: Blood urea nitrogen,

TG: Triglyceride, AST: Aspartate aminotransferase, ALT: Alanine aminotransferase, ALP: Alkaline phosphatase, ED: Effective dose, HD: High dose, PED: Post-effective dose, P. emblica: Phyllanthus emblica

in continuous dosing group of males and females. Interestingly, the increase in RBC and HGB were statistically significant for ED and PED in both sexes, except for females with no effect on HGB content. The results suggested that the supplementation of FPJ affected the hematological parameters. However, all the changes were in the normal range. Hence, supplementation of FPJ was not affect the tested parameters.

The phytochemical content and medicinal property of $P$. emblica has been reported with a possible molecular mechanism [1]. P. emblica fruit extract exhibited cytotoxicity against ovarian, liver and cervical cancer cells, and the toxic effect on ovarian cancer cells was attributed to the activation of autophagy [31-33]. The antiproliferative effect of emblica extracts on cancer cell lines was associated with the activation of apoptotic pathway, and both crude extract and purified compounds (such as quercetin, corilagin, pyrogallol, ellagic, chebulagic, and gallic acids) can inhibit the NF- $\kappa$ B activity $[34,35]$.

The anti-inflammatory effect of hydroalcoholic extract of emblica fruit was reported using induced paw edema in rats. The emblica extract showed edema reduction in a dose-dependent manner, and results were similar to the commercial ant-inflammatory drug and indomethacin [36]. The methanolic extract of emblica fruits $(400 \mathrm{mg} / \mathrm{kg}$ 
of body weight) reduced the carrageenan-induced acute inflammation in rats up to $72.71 \%$ [37].

Guo and Wang [38] reported that aqueous extract of emblica fruit protects the human colon epithelial cells from mitotic abnormalities, and genetic variability by improving the function of spindle assembly checkpoint. The emblica fruit extract was reported for synergetic antimicrobial effect along with antibiotics against Salmonella typhimurium [19].

The changes in phytochemical content, antioxidant property, and other physical properties such as color, odor, taste, and gas formation in LAB LPFJ was reported previously [21]. The study proved that L. paracasei HII01 mediated fermentation process improved the quality of $P$. emblica fruit juice regarding nutritional value and antioxidant property. The authors also suggested that LPFJ can be used as a dietary supplement [21].

\section{CONCLUSION}

As we reported earlier, the prepared FPJ was rich in phytochemicals, antioxidants, and free from pathogenic microbes. The supplementation of different dose of $\mathrm{FHJ}$ does not affect the average body weight gain, internal organs' weight, and tested biochemical parameters significantly. However, hematological parameters were altered significantly on FHJ supplementation. The changes were within the normal range of respective parameters. Hence, the study suggested that the consumption of FPJ was not affected the rodent system in some disagreeable ways. The further detailed study is required to confirm the toxicity of FHJ.

\section{ACKNOWLEDGMENT}

Authors thankfully acknowledge the CMU grant for the support and also acknowledge the Faculty of Pharmacy, and CMU, Thailand, for the necessary provision. All the authors wish to acknowledge the National Science and Technology Development Agency for the support.

\section{AUTHORS CONTRIBUTIONS}

CC involved in the study design and finalization of the manuscript. BSS and PK contributed to data analysis, manuscript preparation, and critical revision of the manuscript. YD, SS, KC, and SP is responsible for wet laboratory experiments. All the authors agree with the content of the manuscript.

\section{CONFLICT OF INTEREST}

There is no conflict of interests.

\section{REFERENCES}

1. Variya BC, Bakrania AK, Patel SS. Emblica officinalis (Amla): A review for its phytochemistry, ethnomedicinal uses and medicinal potentials with respect to molecular mechanisms. Pharmacol Res 2016;111:180-200

2. Perianayagam JB, Sharma SK, Joseph A, Christina AJ. Evaluation ofanti-pyretic and analgesic activity of Emblica officinalis Gaertn. J Ethnopharmacol 2004;95:83-5.

3. Asmawi MZ, Kankaanranta H, Moilanen E, Vapaatalo H. Antiinflammatory activities of Emblica officinalis gaertn leaf extracts. J Pharm Pharmacol 1993;45:581-4.

4. Srinivasan K. Plant foods in the management of diabetes mellitus: Spices as beneficial antidiabetic food adjuncts. Int J Food Sci Nutr 2005;56:399-414.

5. Grover JK, Yadav S, Vats V. Medicinal plants of India with anti-diabetic potential. J Ethnopharmacol 2002;81:81-100.

6. Akhtar MS, Ramzan A, Ali A, Ahmad M. Effect of Amla fruit (Emblica officinalis Gaertn.) on blood glucose and lipid profile of normal subjects and type 2 diabetic patients. Int J Food Sci Nutr 2011;62:609-16.

7. Ngamkitidechakul C, Jaijoy K, Hansakul P, Soonthornchareonnon N, Sireeratawong S. Antitumor effects of Phyllanthus emblica L.: Induction of cancer cell apoptosis and inhibition of in vivo tumor promotion and in vitro invasion of human cancer cells. Phytother Res 2010;24:1405-13.

8. Ojha S, Golechha M, Kumari S, Arya DS. Protective effect of Emblica officinalis (Amla) on isoproterenol-induced cardiotoxicity in rats. Toxicol Ind Health 2012;28:399-411.

9. Zhang YJ, Nagao T, Tanaka T, Yang CR, Okabe H, Kouno I. Antiproliferative activity of the main constituents from Phyllanthus emblica. Biol Pharm Bull 2004;27:251-5.

10. Boll M, Weber LW, Becker E, Stampfl A. Mechanism of carbon tetrachloride-induced hepatotoxicity. Hepatocellular damage by reactive carbon tetrachloride metabolites. Z Naturforsch C 2001;56:649-59.

11. Rahman S, Akbor MM, Howlader A, Jabbar A. Antimicrobial and cytotoxic activity of the alkaloids of Amlaki (Emblica officinalis). Pak J Biol Sci 2009; 12:1152-5.

12. Mehmood MH, Siddiqi HS, Gilani AH. The antidiarrheal and spasmolytic activities of Phyllanthus emblica are mediated through dual blockade of muscarinic receptors and Ca2+channels. J Ethnopharmacol 2011;133:856-65.

13. Pandaand S, Kar A. Fruit extract of Emblica officinalis ameliorates hyperthyroidism and hepatic lipid peroxidation in mice. Die Pharm 2003;58:753-5.

14. Sarkhel S, Chakravarty AK, Das R, Gomes A, Gomes A. Snake venom neutralizing factor from the root extract of Emblica officinalis Linn. Orient Pharm Exp Med 2011;11:25-33.

15. Thirunavukkarasu M, Selvaraju V, Tapias L, Sanchez JA, Palesty JA, Maulik N. Protective effects of Phyllanthus emblica against myocardial ischemia-reperfusion injury: The role of PI3-kinase/glycogen synthase kinase 3beta/beta-catenin pathway. J Physiol Biochem 2015;71:623-33.

16. Kulkarni AP, Kellaway LA, Kotwal GJ. Herbal complement inhibitors in the treatment of neuroinflammation: Future strategy for neuroprotection. Ann N Y Acad Sci 2005;1056:413-29.

17. Kumar V. Potential medicinal plants for CNS disorders: An overview. Phytother Res 2006;20:1023-35.

18. Thakur RS, Ahirwar B. The pharmacological evaluation of medicinal plants for cytotoxicity against various cancer cell lines. Int J Pharm Pharm Sci 2017;9:198-202

19. Mehta J, Jandaik S, Urmila S. Evaluation of phytochemicals and synergistic interaction between plant extracts and antibiotics for efflux pump inhibitory activity against Salmonella enterica serovar typhimurium strains. Int J Pharm Pharm Sci 2016;8:217-23.

20. Sushma KS, Rajeshwari P, Raveesha KA. Comparative study of mycoflora, antibacterial activity and phytochemistry of selected fresh and stored medicinal fruits. Int J Pharm Pharm Sci 2017;9:43-8.

21. Peerajan S, Chaiyasut C, Sirilun S, Chaiyasut K, Kesika P, Sivamaruthi BS. Enrichment of nutritional value of Phyllanthus emblica fruit juice using the probiotic bacterium, Lactobacillus paracasei HII01 mediated fermentation. Food Sci Technol Campinas 2016;36:116-23.

22. Woraharn S, Lailerd N, Sivamaruthi BS, Wangcharoen W, Peerajan S, Sirisattha S, et al. Development of fermented Hericium erinaceus juice with high content of L-glutamine and L-glutamic acid. Int J Food Sci Technol 2015;50:2104-12

23. Woraharn S, Lailerd N, Sivamaruthi BS, Wangcharoen W, Sirisattha S, Peerajan $\mathrm{S}$, et al. Evaluation of factors that influence the L-glutamic and $\gamma$-aminobutyric acid production during Hericium erinaceus fermentation by lactic acid bacteria. Cyta J Food 2016;14:47-54

24. Chaiyasut C, Sivamaruthi BS, Makhamrueang N, Peerajan S, Kesika P. A survey of consumer' opinion about consumption and health benefits of fermented plant beverages in Thailand. Food Sci. Technol Campinas. 2018;38(2):299-309.

25. Woraharn S, Lailerd N, Sivamaruthi BS, Wangcharoen W, Sirisattha S, Chaiyasut C. Screening and kinetics of glutaminase and glutamate decarboxylase producing lactic acid bacteria from fermented Thai foods. Food Sci Technol Campinas 2014;34:793-9.

26. Komatsuzaki N, Shima J, Kawamoto S, Momose H, Kimura T. Production of $\gamma$-aminobutyric acid (GABA) by Lactobacillus paracasei isolated from traditional fermented foods. Food Microbiol 2005;22:497-504

27. Chaiyasut C, Woraharn S, Sivamaruthi BS, Kesika P, Lailerd N, Peerajan S. Lactobacillus fermentum HP3 mediated fermented Hericium erinaceus juice as a health promoting food supplement to manage diabetes mellitus. J Evid Based Integrative Medicine 2018;23:1-9.

28. Itthipanichpong C, Ousavaplangchai L, Ramart S, Thamaree S, Tankeyoon M. Acute toxicity and subacute toxicity study of Phyllanthus emblica. Chula Med J 1987;31:367-76.

29. Mokkhasmit M, Swatdimongkol K, Satrawaha P. Study on toxicity of Thai medicinal plants. Bull Dept Med Sci 1971;12:36-65.

30. Chaiyasut C, Pattananandecha T, Sirilun S, Suwannalert P, Peerajan S, Sivamaruthi BS. Synbiotic preparation with Lactic acid bacteria and 
inulin as a functional food: In vivo evaluation of microbial activities, and preneoplastic aberrant crypt foci. Food Sci Technol Campinas 2017;37:328-36.

31. De A, Papasian C, Hentges S, Banerjee S, Haque I, Banerjee SK. Emblica officinalis extract induces autophagy and inhibits human ovarian cancer cell proliferation, angiogenesis, growth of mouse xenograft tumors. PLoS One 2013;8. Article ID: e72748.

32. Zhu X, Wang J, Ou Y, Han W, Li H. Polyphenol extract of Phyllanthus emblica (PEEP) induces inhibition of cell proliferation and triggers apoptosis in cervical cancer cells. Eur J Med Res 2013;18. Article ID:46.

33. Shivananjappa MM, Joshi MK. Influence of Emblica officinalis aqueous extract on growth and antioxidant defense system of human hepatoma cell line (HepG2). Pharm Biol 2012;50:497-505.

34. Ho HH, Chang CS, Ho WC, Liao SY, Wu CH, Wang CJ. Anti-metastasis effects of gallic acid on gastric cancer cells involves inhibition of NF-$\mathrm{B}$ activity and downregulation of PI3K/AKT/small GTPase signals. Food Chem Toxicol 2010;48:2508-16.
35. Ho HH, Chang CS, Ho WC, Liao SY, Lin WL, Wang CJ. Gallic acid inhibits gastric cancer cells metastasis and invasive growth via increased expression of RhoB, downregulation of AKT/small GTPase signals and inhibition of NF-kappaB activity. Toxicol Appl Pharmacol 2013;266:76-85

36. Golechha M, Sarangal V, Ojha S, Bhatia J, Arya1 DS. Antiinflammatory effect of Emblica officinalis in rodent models of acute and chronic inflammation: Involvement of possible mechanisms. Int $\mathrm{J}$ Inflam 2014;2014. Article ID:178408.

37. Middha SK, Goyal AK, Lokesh P, Yardi V, Mojamdar L, Keni DS, et al. Toxicological evaluation of Emblica officinalis fruit extract and its antiinflammatory and free radical scavenging properties. Pharmacogn Mag 2015;11 Suppl 3:S427-33.

38. Guo X, Wang X. Phyllanthus emblica fruit extract activates spindle assembly checkpoint, prevents mitotic aberrations and genomic instability in human colon epithelial NCM460 cells. Int J Mol Sci 2016;17. Article ID:1437. 